\title{
Testing Technology
}

SANDIA NATIONAL LABORATORIES - Albuquerque, NM • Livermore, CA • Operated for the U.S. Department of Energy by AT\&T

\section{Inside this issue}

\section{New technigue lmeges cunent in KC conductors \\ Magnetic force microscopy detects cument without surfoce contact 1 \\ Teating news in brief ...2

\section{Tunable resonant \\ fixture shocks sitellite components \\ Pyroshock simulation tests electronics for space and defense}

\section{Insulated camera g-ts} hot pictures

Burning fuel not too hot for dota collection at TTR

Solar cell test gystem achleves new occuracy

Spectrol response and laser scanning find deficiencies ...

\section{Special insert:}

STAns reaches new helghts with first lounch from krous

Three-stoge vehicle delivers poyload to Kwajalein

\section{New technique images current in IC conductors}

\section{Magnetic force microscopy detects current without surface contact}

The complexity of integrated circuits is constantly increasing, with hundreds of thousands of transistors packed onto a single chip and feature sizes in the submicron range. With this increased complexity, the difficulty of analyzing ICs has also increased. To assess

A magnified view of a cantilever with a magnetic tip" attached. As the tip passes over a current-carrying circuit, the amplitude of the tip's vibration increases, indicating the presence of the current.

IC performance or to validate a computer model of IC operation, researchers must know both the current and the voltage at any given point in an IC. While it is straightforward to determine voltages with reasonable accuracy using electron beam techniques, sensitive, noninvasive techniques for measuring IC currents have not been available up to this time.

Recently, researchers in Sandia's Failure Analysis Department developed an approach for determining currents in IC conductors by detecting the magnetic fields induced by those currents. Using a scanning probe microscope, they developed a novel application of magnetic force microscopy to image the local magnetic field gradients above the IC surface. This technique, Magnetic Force Microscopy/Current Contrast Imaging, is a unique application of commercially available scanning probe microscope equipment.

In MFM/CCI, the force sensor is a tiny permanent magnet that is attached to a cantilever. The cantilever is vibrated near its resonance frequency and scanned over the sample. Local magnetic field gradients exert a force on the tip, which changes the resonance properties of the cantilever. The change in resonance is used to image the direction and magnitude of the magnetic field gradient, which is directly related to the IC currents.

$\mathrm{MFM} / \mathrm{CCI}$ can determine both the magnitude and direction of IC currents with a sensitivity of 1 milliamp DC and 1 microamp AC. The thousand-fold increase in sensitivity for $\mathrm{AC}$ currents arises because the vibrating cantilever behaves like a simple harmonic oscillator. When a simple harmonic oscillator 


\section{Testing news in brief}

Calibrating solar cells can be cheaper, faster, more iccurate

Sandia researchers in the Photovoltaic Device Measurement laboratory, in collaboration with NIST, have developed a new method for calibrating primary reference solar cells. Using a standard quartz-tungsten-halogen lamp at NIST, the new method can be done indoors in minutes, while the old ASIM-approved method, expensive and time-consuming, had to be done outdoors. The new method can also replace the expensive calibration procedures used by the space photovoltaic industry, which are based on high-altitude aircraft and balloon flights. The new method is more accurate and could ensure that properly referenced solar cells become more widely used.

Barry Hansen, Org. 6219, (505) 844-2727, or Dave King, Org. 6219, (505) 844-8220

Radar cross-section images compared with new algorithms

Test system evaluates large battery systems

Fiber-optic shock sensor has verification: uses

Exterior intrusion sensors tested where they will work
Sandia radar engineers, studying rotating targets, have used new algorithms to produce high-resolution, two-dimensional radar images for visual evaluation. New algorithms can also determine if targets match over wide bandwidths and large aspect ratios. Researchers confirmed these capabilities by stepping through discrete frequency intervals and sweeping over bandwidths up to 16 gigahertz. The technique can be used to evaluate stealth technology or nondestructively test almost any material, whether electrically conducting or nonconducting, for voids, gaps, and homogeneity.

Dale Cooper, Org. 9813, (505) 844-9451

Sandia's new battery test system can perform life cycle tests at constant current or power levels, peak power tests, frequency regulation tests, and electric vehicle driving profile tests for large battery systems producing up to 20 kilowatts of power. Special software controls the 20-kilowatt tester and synchronizes the collection of data. The software can control almost any type of battery tester with little or no modification.

Gus Rodriguez or Casey Woods, Org. 2525, (505) 844-0494

Researchers at Sandia are patenting a fiber-optic sensor that provides a continuous measure of the length of its own fibers and thus detects changes in fiber integrity that may be caused by a shock, such as that from an underground nuclear explosion. The Defense Nuclear Agency has sponsored the research leading to the device in its search for sensors that are inherently immune to electromagnetic interference. The sensor uses optical fibers uniformly doped with neodymium, a fluorescing "impurity." When excited with a steady laser source, the neodymium atoms fluoresce, and some of that fluorescence returns along the fibers to a detector. When the fibers are continuously sinortened by a shock wave, the detector output drops as the returning fluorescence decreases. The device could also be used industrially in, for example, structural failure diagnostics. Jonathan Weiss, Org. 22.31, (505) 845-7536, or Salvador Lopez, Org. 9312, (505) 845-7818

lo support DOE's security needs, Sandia runs a range for testing exterior intrusion detection sensors. The Exterior Intrusion Sensor Field can test the capabilities of the sensors in an outside environment that provides a wide range of environmental conditions. Year-round testing can evaluate the reliability of a sensor system and determine its effectiveness, evaluating such faults as nuisance alarms or diminished detection capabilities.

Larry Miller, (Ors. 9549, (505) 84.5-3121 
is driven by an external force at its resonance frequency, the vibration amplitude grows very large. Thus, applying an AC current to an IC conductor (and therefore modulating the magnetic field gradient) at the resonance frequency of the cantilever has a much larger effect on the cantilever than a DC gradient of the same magnitude. (The cantilever is vibrated by piezoelectric elements responding to a control current, and the same signal is used to modulate the AC current.)

"This technique can, potentially, image the current over an entire chip," says Ann Campbell, of the Failure Analysis Department. Because the sensor is not in contact with the surface of the chip, the chip is not damaged. Furthermore, the resolution of the technique allows analysis of individual transistors. "We need smaller, sharper sensor tips and an improved sample mounting stage to generate the images we need," continues Campbell, "but we can see the uses of this technique now."

$\mathrm{MFM} / \mathrm{CCI}$ will be useful in integrated circuit failure analysis, design verification, and model validation to map the current paths on integrated circuits. In particular, MFM/CCI will be used to determine the location(s) of elevated current(s) on defective integrated circuits and to determine and verify the operation of functional integrated circuits. $\mathrm{MFM} / \mathrm{CCI}$, combined with electron beam voltage contrast imaging, will produce a complete picture of IC operation.

Two manufacturers of scanning probe microscopes have expressed interest in developing commercial versions of $\mathrm{MFM} / \mathrm{CCl}$, and electronics manufacturers are interested in using this approach. The MFM/CCl technique should prove quite cost-effective. A complete system will probably cost around $\$ 200,000$. In comparison, electron-beam test equipment can cost $\$ 500,000$ or more. $\mathrm{MFM} / \mathrm{CCl}$ will also be useful for examining currents and magnetic effects on other electronic devices, such as flat panel displays, optoelectronic devices, miniature inductors, miniature transformers, and superconducting devices. 团

For more information, call

Ann Campbell, Org. 2275, (505) 844-7452, or

Ed Cole, Org. 2275, (505) 844-1421.
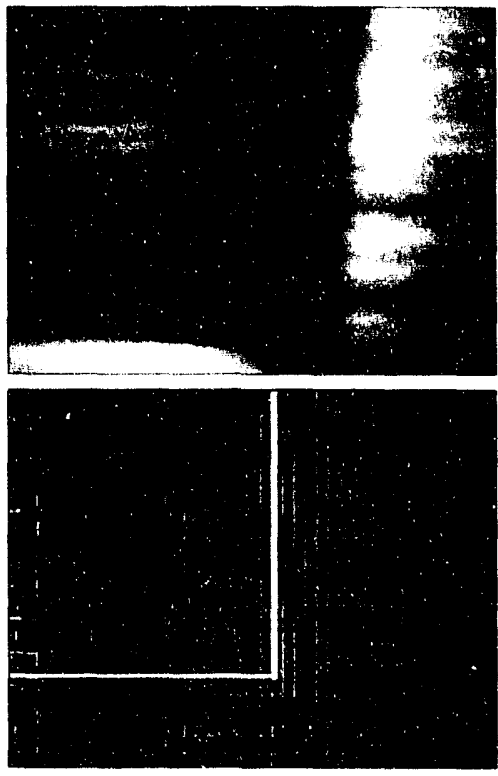

The top photo shows the $\mathrm{MFM} / \mathrm{CCl}$ image of a high-current path in a damaged IC. The bright-to-dark contrast occurs along the path of the conductor and corresponds to the change in direction of the magnetic force gradient. The lower photo is an optical micrograph of the damaged IC; the elevated current path that was determined from the top image is indicated in white.

\section{Geomaterials testing improved with "true triaxial" loading}

\section{New tester puts pressure on rocks as if they were nine kilometers underground}

Rock, still the most common material encountered or used in construction, is found in many activities, from the foundations and bases of houses, roads, or dams, to underground storage caverns or the boreholes of oil wells. If concrete (essentially, a rock-like material) is included, the near-universal use of rock in human building activities is clear, as is the need for a fuller knowledge of the strength and mechanical properties of rock in all its forms. Such knowledge has been limited by available research facilities, which have not generally been able to simulate the in situ conditions of geomaterials. Sandia researchers have designed and built a test system for simulating and controlling the most general natural loading conditions of geomaterials in the earth up to depths of 9 kilometers $(30,0(0)$ feet). Using prismatic samples
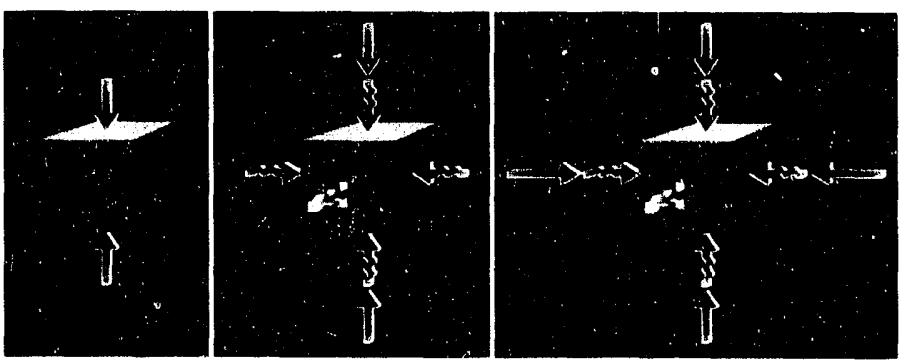

The three states of loading are depicted schernatically in this figure. The (virtual) cube shown represents a basic building block of the rock mass in a dam foundation, next to a highway tunnel, in an oil res :rvoir, or along a geologic fault deep in the earth's crust. The responses of this building block to changes in loading determine the stability of the dam, tunnel, or geologic fault. Sandia's rock mechanics facility can generate "true triaxial" loading of rock samples to study their response to varying loads along the three mutually perpendicular axes. 


\section{Geomaterials under pressure}

Geomaterials exhibit unique properties that distinguish them from other solids, including metals and composites. First, geomaterials are very much stronger in compression than they are in tension. Second, geomateriais are stiff and brittle under simple unidirectional loading, yet become ductile when uniaxial loading is preceded by the application of a uniform (hydrostatic) pressure. (That is, when one axis is loaded while the entire sample is under pressure, geomaterials become deformable.) Third, rocks generally deform nonlinearly and increase in volume as the applied loads are raised. (This is called "dilatancy," in which volume increases are caused by the formation of grain-sized cracks in the material.) The fourth property is that the loadbearing ability of geomaterials under compression increases dramatically as the applied pressure increases. Finally, the response of geomaterials changes when uniform pressurization is followed by the application of loads in not only one but two mutually perpendicular directions. This is "true triaxial" loading and most closely simu. lates the general conditions of the geomaterials in the earth's crust. The responses of geomaterials to this true triaxial loading are not easily derived from other types of loading. of rock, loads are applied on two sets of faces by specially designed hydraulic jacks inside a fluid-filled pressure vessel. The third pair of faces is pressurized directly by raising the fluid pressure. The sample's two accessible faces (the pair exposed directly to the pressurized fluid) are instrumented to monitor how the rock deforms and eventually fails as the loads are increased. "Mechanical responses in rock can change dramatically when different loading conditions are applied," notes Wolfgang Wawersik, of Sandia's Geomechanics Department. "It is essential that we develop constitutive models for geomaterials and extend our knowledge of such responses." Such knowledge is important to the oil and gas industries, mining, and the construction industry, among others. Sandia researchers have already used the device to evaluate borehole stability problems, working with Oryx Energy Company under the (Oil Recovery Technology Partnership Program. 'The new test equipment is a key element in a study of strain localization in geomaterials sponsored by DOE's Basic Energy Science research program, where Sandia is working with Northwestern University. As Wawersik says, "Extending our knowledge of the basic mechanics of rock is essential to a number of industries - and our new tester will be an important tool in providing that knowledge." 团

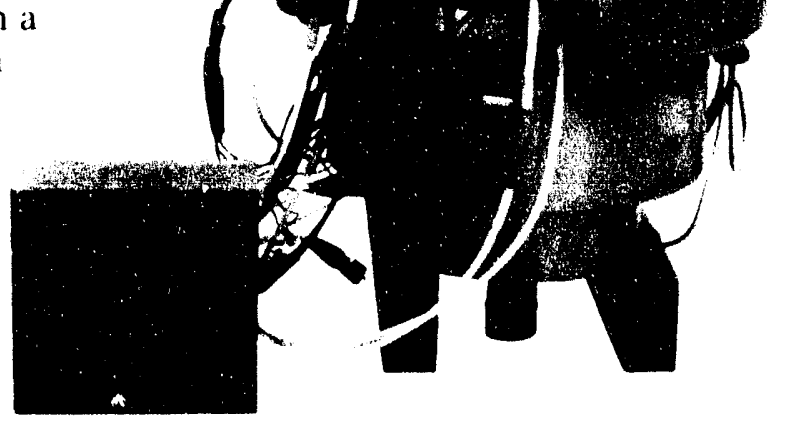

The test device with a typical rock sample. The system recreates the general conditions of rock deep underground by pressurizing all six faces of a prismatic sample and placing additional loading on four of the faces by using hydraulic jacks.

\section{Tunable resonant fixture shocks satellite components Pyroshock simulation tests electronics for space and defense}

ihe Strategic Targeting System II is a three-stage missile that can carry a variety of payloads, including simulated IC.BM reentry vehicles or, potentially, small satellites or research payloads (see special insert to this issue). like any other multistage rocket, SIARS II can generate significant forces during stage separation. When stage separation devices detonate and push away a used rocket engine, the pyroshock environment that is created could damage satellite components.

Sandia researchers recently built a new tester to simulate this environment more effecrively, which will help qualify components to survive the pyroshock. 


\section{Special insert to Testing Technology}

On February 26, 1993, the largest vehicle ever launched by Sandia at the Kauai Test Facility lifted off at 9:45 a.m. The Strategic Target System Flight Test Unit 1 made history for Sandia in other areas, as well. Technologies used for the first time by Sandia at KTF for the STARS FTU-1 included thrust vector control instead of roll stabilization during flight and a vertical launch instead of a guiding rail launcher. The STARS launch capped 30 years of Sandia experience in rockets, missiles, and space systems, and moved Sandia's launch resources into a new regime of lift capacity and potential orbital capabilities.

The primary objectives of FTU-l were to verify the design of the vehicle and evaluate the flight performance of the system. FTU-l delivered a single payload to a broadocean-area impact point north of Kwajalein Atoll in the Pacific Ocean. The STARS missile consists of refurbished and recertified first- and second-stage boosters from the Polaris A3 fleet ballistic missile, as well as the interstage between the first and second stages, and the nose fairing. The boosters included the thrust vector control systems. To these elements was added a newly designed third-stage section that contained several new Sandia-designed systems. These included the guidance and control system with the SANDAC flight computer and the inertial measurement unit, the flight termination system electronics, the arming and firing system, the thrust vector control servo electronics, and a third-stage motor specifically design-optimized for this vehicle.

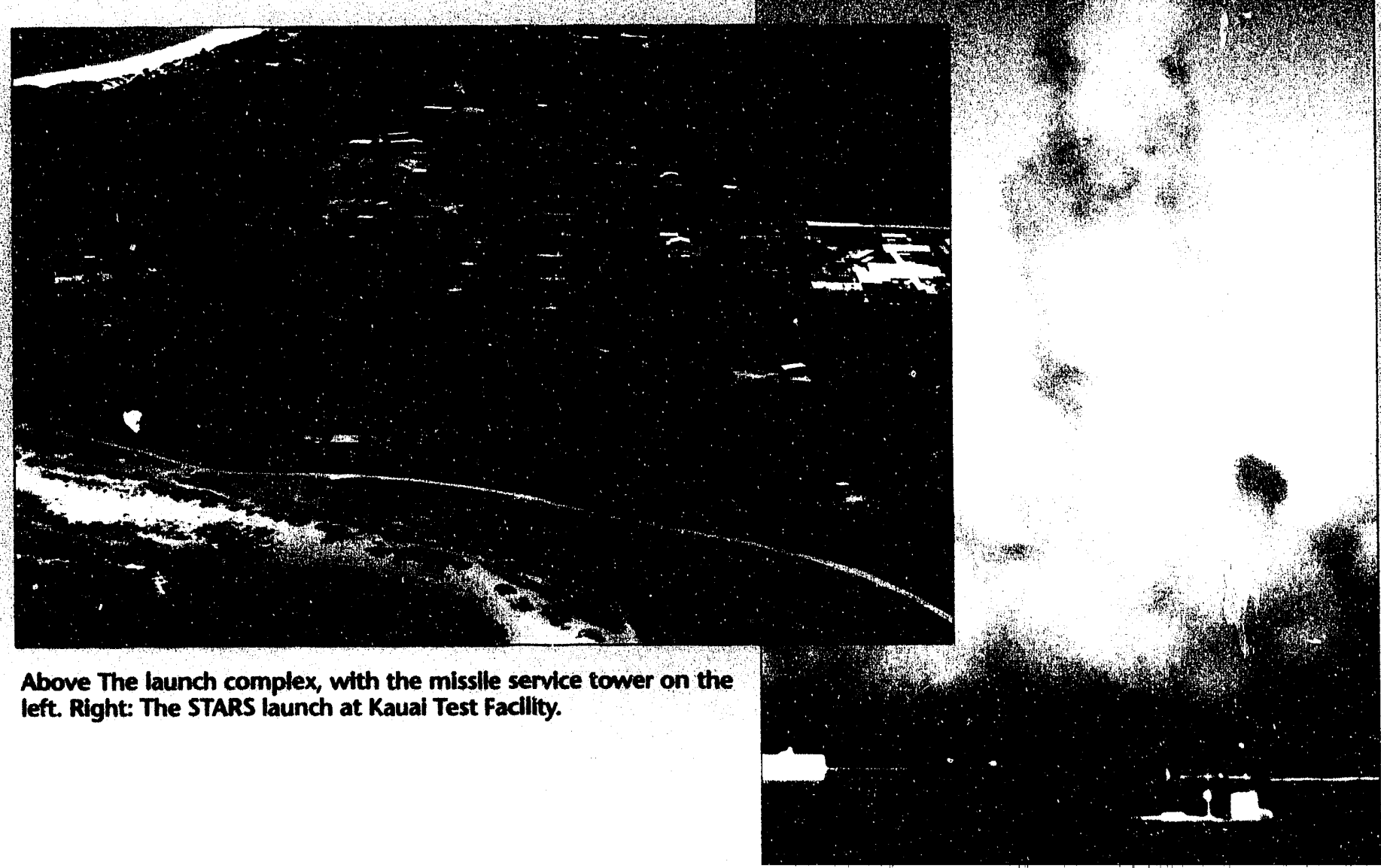


Sandia engineer Margaret Weber installs the secondstage motor ignition cable (thin black cable) in its mounting bracket. The white cable leading to the center of the forward dome of the second stage is the motor transducer cable.
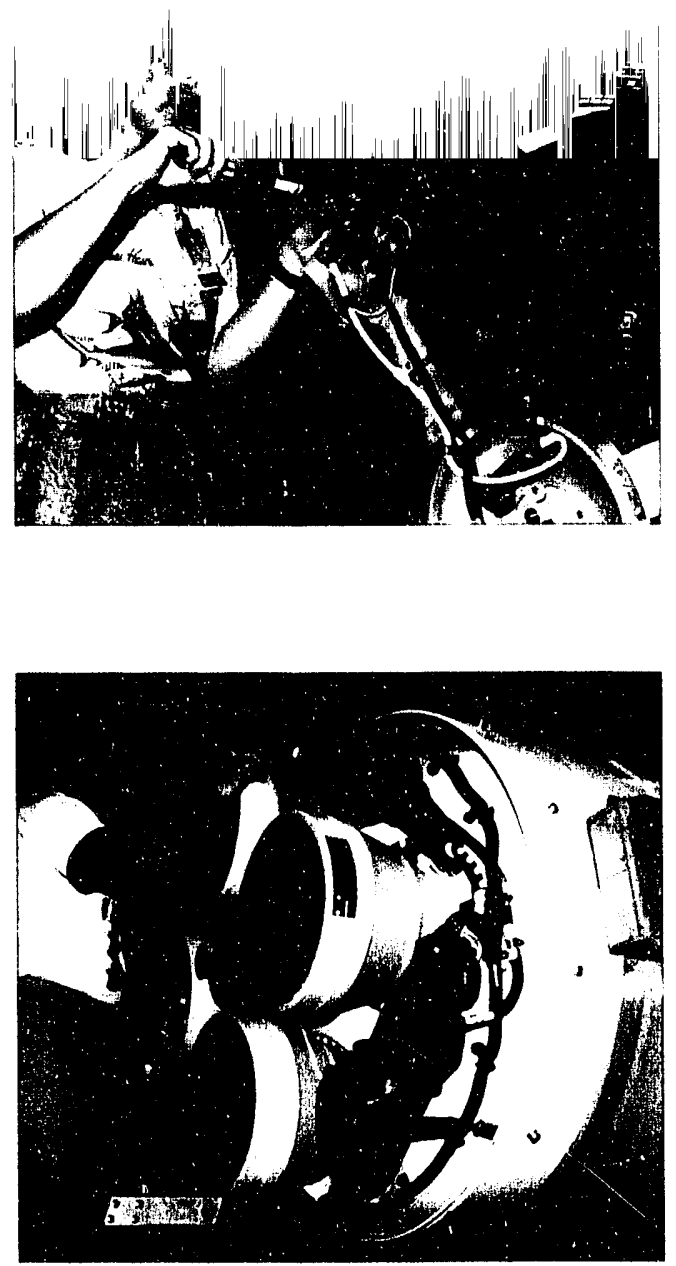

Bob Mata inspects the thrust vector control system for the first stage. The brownishorange bundles are the hydraulic actuator packages; the cylindrical assembly centered between the four thrust nozzles is the hydraulic power distribution package, which supplies electrical power to the actuator packages.

Gerry Gay installs the electronics (blue box) for the Flight Termination System on the forward dome of the firststage motor, while Steve Lautenschleger records the work on the missile processing procedure checklist.

Inside the missile assembly building, engineers prepare the STARS missile for the final system checkout prior to complete assembly and movement to the launch pad.
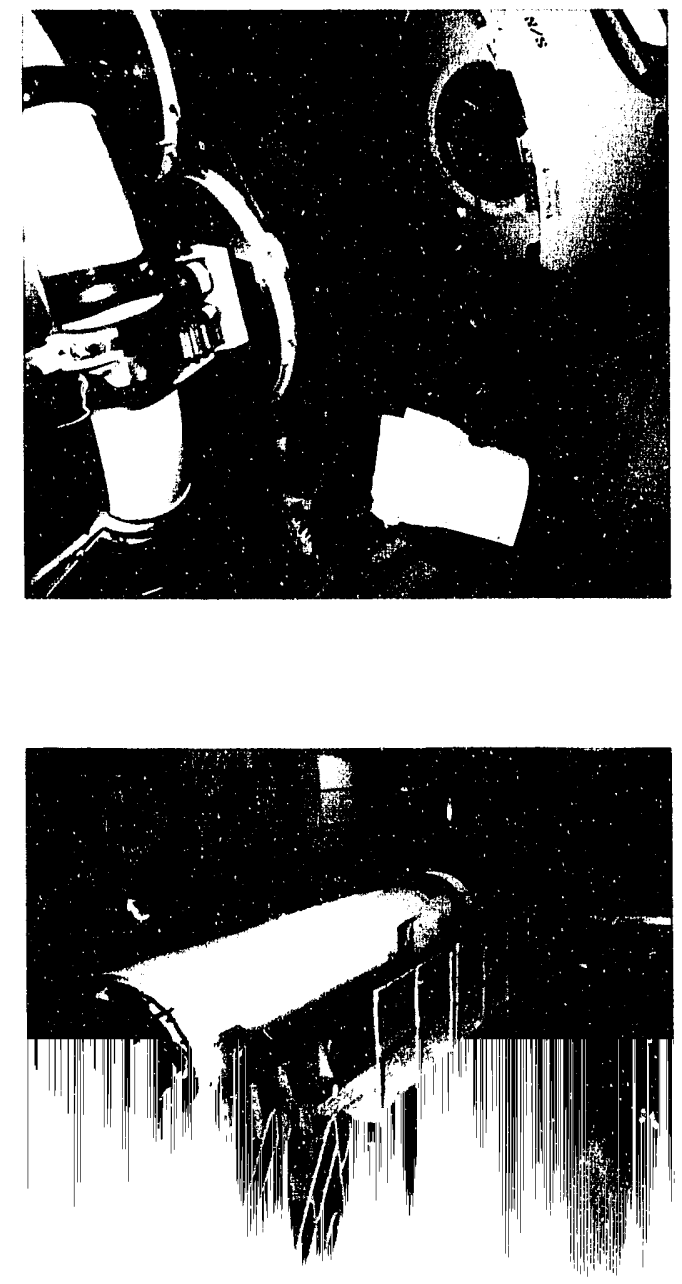

"One of the hardest jobs was collecting the Polaris components and refurbishing them," recalls Bob Mata, the lead missile engineer. "We added motor reinforcements to the first stage, cleaned and refurbished the igniter nozzles and thrust vector control components for the first and second stages, and refurbished the nose fairings." When reassembled with the new third stage, the STARS missile stands over 10 meters tall, has a 1.3 meter diameter, weighs 16,600 kilograms, and delivers 333,000 newtons of thrust at liftoff.

Sandia began working on the STARS program in early 1986 . 'The vehicle's purpose is to deliver payloads to the U.S. Army Kwajalein Atoll Range with ICBM reentry conditions. A study of available booster assets and their condition was undertaken, resulting in a decision to utilize selected components of the retired Polaris A3 missile. Once this decision was reached, Sandia refurbished and recertified those assets and designed the new subsystems.

It takes approximately thirty days to prepare the missile for flight at the Kauai Test Facility. The entire missile is shipped in sections to the Pacific Missile Range Facility, the host range for the test facility. Engineers and technicians perform rigorous inspections and tests on the navigation, attitude control, and thrust vector control systems on all three stages, and check for pressure leaks on the first and second stage boosters. After a system test, the assembled missile travels to the launch pad, where it is placed on the launch stand. The missile service tower rolls to cover the missile and launch stand and provide access to the upper stages. At this point, the payload is mated to the missile for a complete end-to-end test. Practice countdowns and launch reviews are held before arming and launching the missile.

The next launch, currently scheduled for mid-summer, will carry research payloads to a target point near the Kwajalein range complex, where radars and sensors will acquire data from the experiments. This vehicle will carry a (ilobal Positioning System receiver and antennas in a development mode, demonstrating that stand-alone Gips receivers can operate properly while llying a 


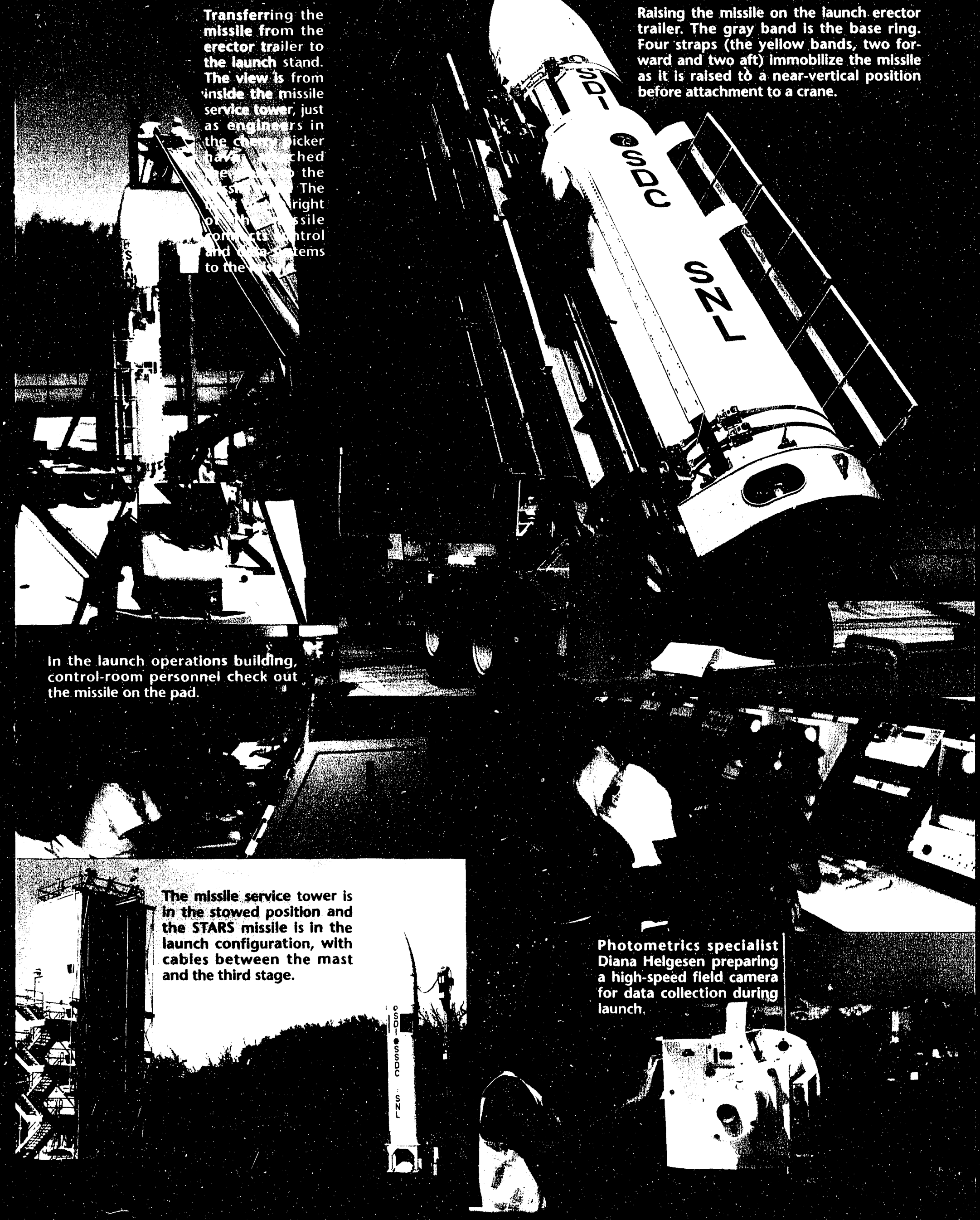


typical STARS trajectory. In future missions, the GPS position and velocity solutions will be incorporated into the guidance system to reduce navigational error and increase the system's cross-range targeting accuracy.

The FTU-l mission achieved all of its primary objectives of verifying and validating the design of the STARS vehicle. The operational phase of the program will now continue, with design improvements to support a variety of flight profiles and mission objectives. The work for the STARS project was performed for the U.S. Army Spacr and Strategic Defense Command.

"This is a work-horse vehicle," says Eric Schindwolf, manager of Sandia's Large Rocket Systems Department. "It can have wide applications for many programs, both government and commercial." For example, the trajectory can be shaped to deliver reentry targets with ICBM velocities and path angle, or, by further modification, like an intermediate range ballistic missile. The missile can also simulate a high-end theater missile defense target or meet high-altitude requirements for satellite encounter missions. This vehicle can also perform as a heavy experiment carrier ( 1000 pounds, almost 500 kilograms, payload) to achieve very high altitudes or to provide many minutes of microgravity. Finally, with the addition of an appropriate fourth stage, STARS can launch light satellites on orbital missions. This vehicle adds a new and versatile capability to the Sandia inventory of rocket systems. 团

For more information, call

Bob Mata, Org. 2725, (505) 845-9227, or

Eric Schindwolf, Org. 2725, (505) 844-2026.

Ignition and lift-off of the STARS FTU-1 at Kauai Test Facility.
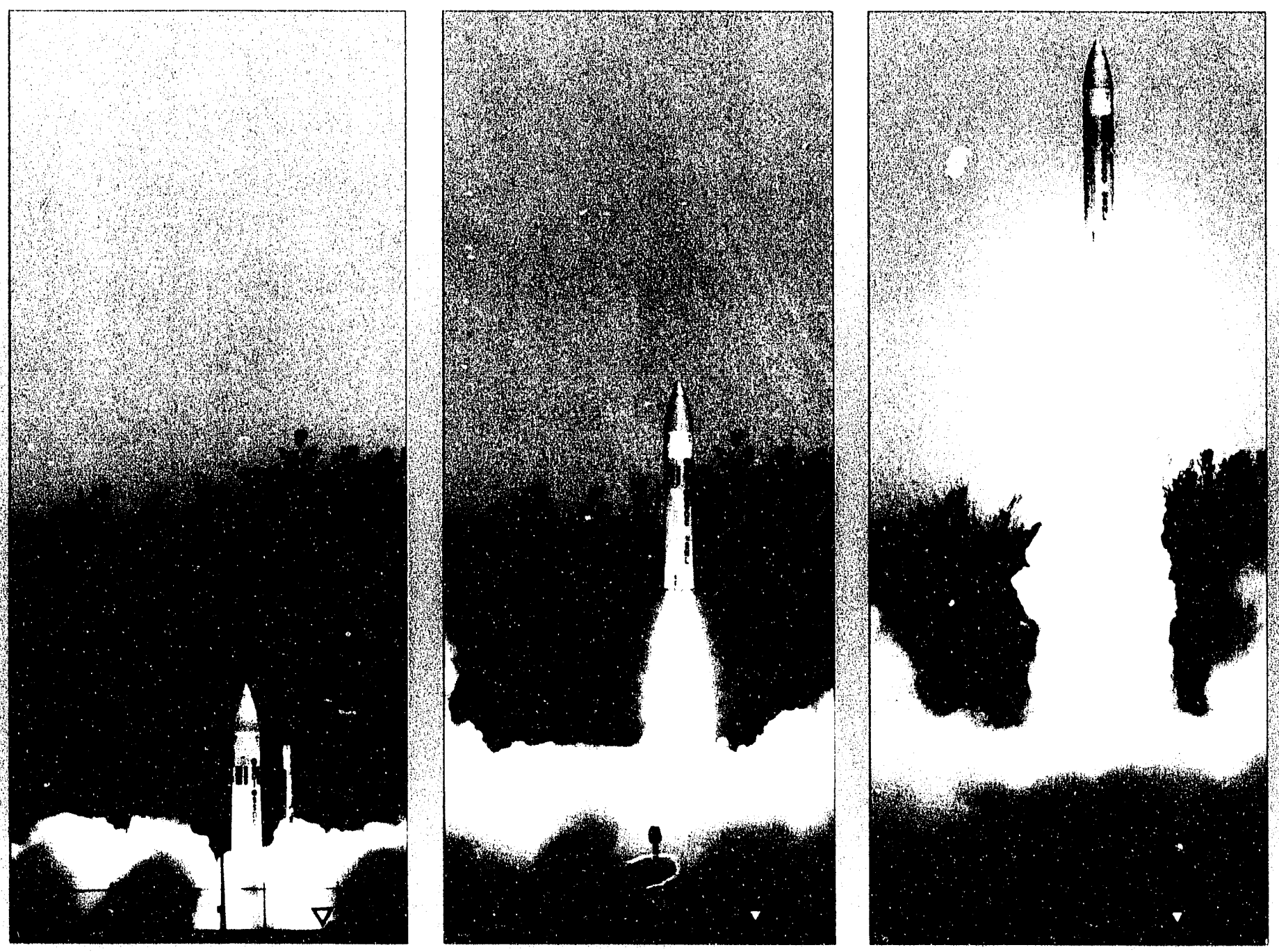
Pyroshock during stage separation and other events excites the structure into a resonant response characterized by a high $\mathrm{g}$, high frequency acceleration transient. The acceleration forces (g forces) typically range from 1,000 to $20,000 \mathrm{gs}$, with frequencies greater than 1,000 hertz.

"We built one pyroshock simulator back in the early ' 80 s," recalls Neil Davie, of Sandia's Mechanical Shock Laboratory. "It was better than drop test machines or shakers, but the resonant structure had to be changed out for each different vibration frequency:" The earlier tester used a massive aluminum plate as a resonant fixture, designed so that its first bending mode corresponded to the dominant frequency in the desired pyroshock environment.

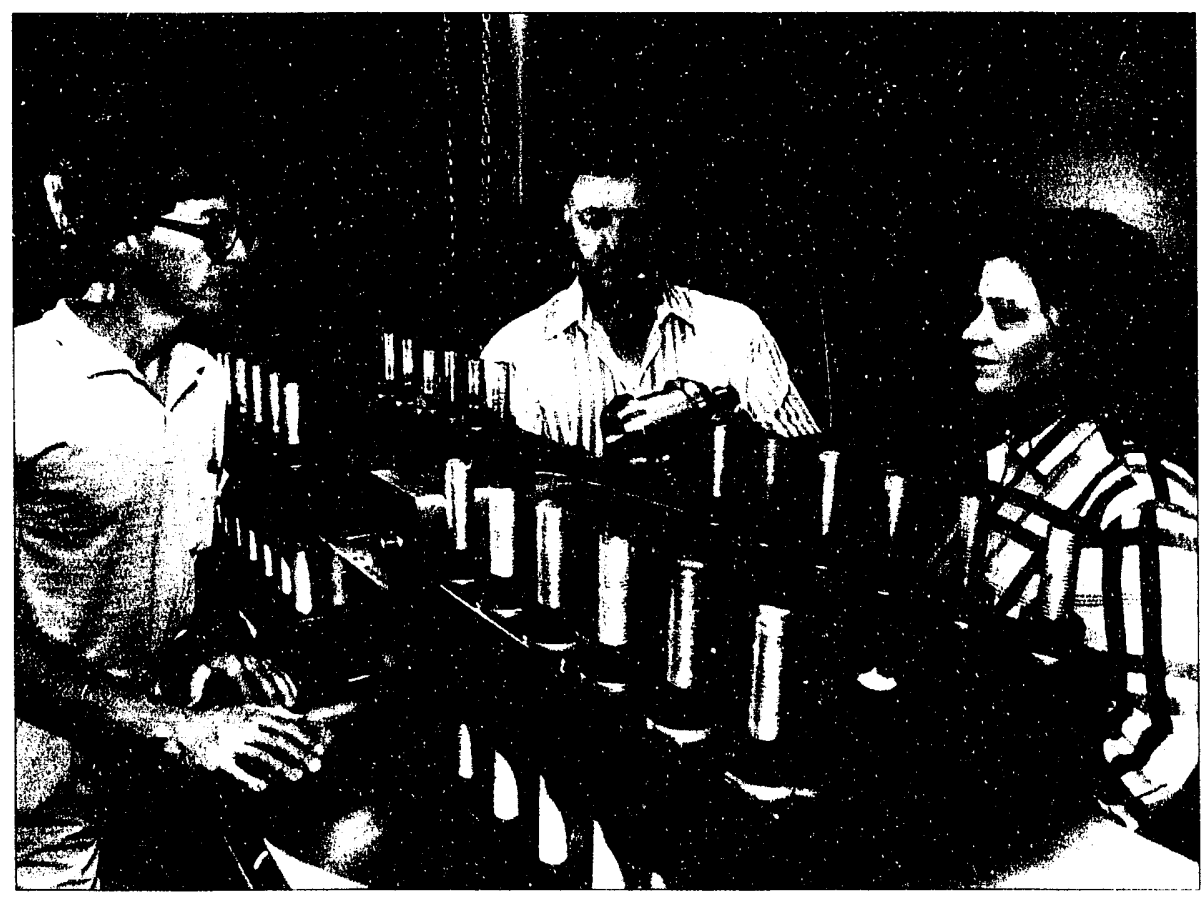
The amplitude of the simulated pyroshock could be adjusted by increasing or decreasing the impact speed of a projectile from a 75-millimeter air gun. However, when a pyroshock with a different dominant frequency was required, a different resonant fixture was needed. The laboratory needed a significant fixture inventory in order to maintain a test capability covering a reasonable frequency range.

Now, researchers have developed a new pyroshock simulation method that eliminates the need for a resonant fixture inventory. The new method uses a single tunable resonant beam instead of numerous individual fixtures. Each end of the aluminum beam is clamped to a massive (3,200 kilogram) concrete and steel base. The resonant frequency of the beam can be infinitely adjusted like a tuning fork by moving the clamp positions to change the free span length of the beam. The bending frequency is approximately predicted by the simple equation for a beam with fixed ends. The resonant beam is 10 centimeters thick by 25 centimeters wide by 183 centimeters long and can carry components with bases up to 30 by 30 centimeters. An air gun located below the center of the beam fires a projectile upward to strike the bottom surface of the beam. Components are mounted directly opposite the impact point on the top of the beam.

The new resonant test fixture was built to test satellite components, which tend to be larger than the weapon components usually tested in the Shock Lab. The fixture has already been used to qualify components for the STARS II missile and is now testing electronic components for a new project. The success of the tester has led to the development of a larger resonant fixture, capable of testing components for large satellites; these components could have bases up to 60 by 60 centimeters.

"These tunable resonant fixtures have given us much more flexibility," says Davie. "We can tune them to any desired vibration frequency, match a required amplitude with the adjustable air gun, and do it without changing out the resonant beam itself. We can also handle much larger components than before." 四

For more information, call

Neil Davie, Org. 2742, (505) 844-6431, or

Vesta Bateman, Org. 2742, (505) 844-0401.

Neil Davie, Fred Brown, and Vesta Bateman with the tunable resonant fixture for simulating pyroshock on satellite components. The large nut-and-bolt assemblies are part of the clamping system that determines the vibrational frequency of the aluminum plate on which the components are mounted. 


\section{The camera had to be kept below the ambient temperature of the test unit.}

The PEX container inside the simulated bomb case.

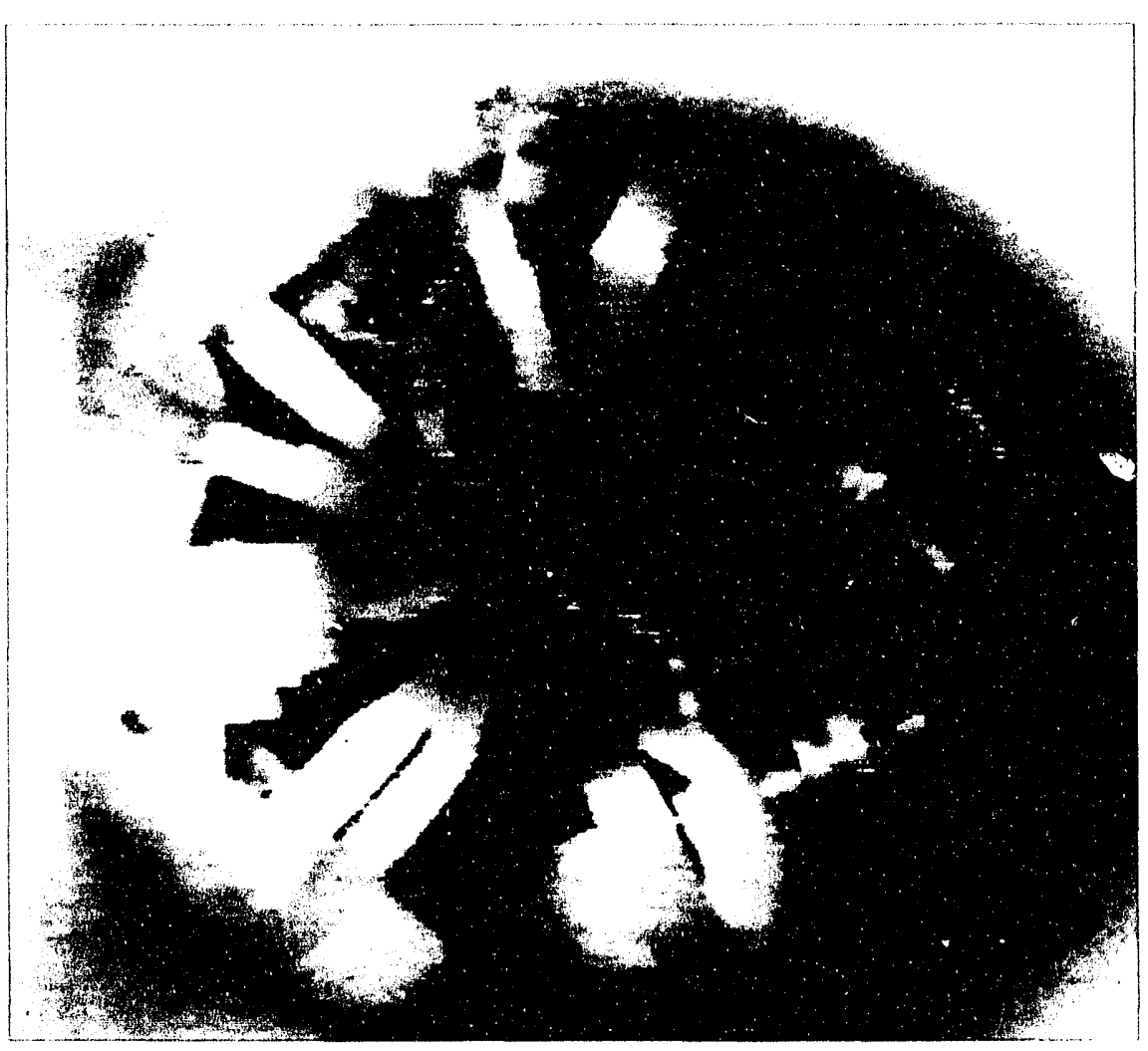

\section{Insulated camera gets hot pictures} Burning fuel not too hot for data collection at TTR

As part of the safety requirements for U.S. nuclear weapons, researchers test the weapons' explosive components in all non-use conditions, and accidents involving fire form some scenarios. When researchers had to test a Paste Extrudable Explosive main charge in burning fuel, Salıdia's Photometrics and Environmental Test departments cooked up a video camera setup that brought home the pictures. A sacrificial video camera mounted inside a simulated weapon during the test provided real-time images of the explosive as it was heated and eventually destroyed.

Sandia weapons testers wanted to determine the response of a PEX storage vessel to transient heating, and used the flames from a 300-gallon pool of burning jet fuel to do so. The PEX vessel was placed inside a simulated bomb case (a 40-centimeter-diameter steel tube) suspended one meter above the pool of fuel. The fuel, once ignited, was expccted to burn for 30 minutes, while the PEX unit itself might only survive five minutes in such a harsh environment. Although the paste extrudable explosive should simply burn, Sandia conducted the test at a remote site on Sandia's Tonopah Test Range in case of explosion.

During such a test, thermocouples measure internal temperatures, and video footage is usually limited to exterior views of the test. However, a series of images from inside the steel pipe would give a visual indication of where and how the PEX vessel eventually failed. No camera could endure the expected $1,800^{\circ} \mathrm{F}$ temperatures for the necessary five minutes, so the camera specialists created a protected video system for intcrior views during the test.

In order to survive, the camera had to be kept below the ambient temperature of the test unit. There was also a potential problem with smoke obscuring the PEX vessel as the temperature rose. A small camera wrapped with thermal insulation and placed in a stream of externally supplied nitrogen gas solved both problems. The electrical cables for the camera and the gas supply line outside the unit were insulated as well, since they, too, were exposed to the flames. The nitrogen traveled the length of the unit and exited through the right end cap vent, taking with it smoke and fumes that could obscure the camera's view of the PEX vessel.

The camera chosen for this task was a monochrome, silicon (CCD video camera designed for surveillance applications. It was moderately small, had good light sensitivity and an automatic electronic shuttering capability, and was relatively inexi)ensive (since it would be expended in the test). Two 75-watt halogen lamps placed beside the camera provided the minimum light needed for cold recording, while the near-infrared energy radiated from the walls of the steel pipe during the test was ten times brighter. 
The test was indeed a success, since the internal camera provided good testtime images. The camera survived for the required five minutes, and, despite occasional internal smoke, recorded images that clearly showed the time and position when the explosive container vented. The loss of the video image coincided with the container venting, indicating that the camera might have survived longer if the thermal environment had been the only consideration.

"We found an inexpensive way to capture pictures that no camera could get before," says Gary Phipps, of the Photometrics Department. "Insulating and cooling the camera let us use it in an environment where it just couldn't survive without such support. We'll use this again whenever we need to see what's going on inside a thermal test." 团

For more information, call

Gary Phipps, Org. 2752, (505) 845-8269,

Leroy Perea, Org. 2752, (505) 845-3209, or

Floyd Mathews, Org. 2761, (505) 845-3174.

\section{Solar cell test system achieves new accuracy}

\section{Spectral response and laser scanning find deficiencies}

Sandia's Photovoltaic Technology Evaluation Department has developed a solar-cell test system with unique repeatability and accuracy. The Spectral Response/Laser Scanning system allows two views of solar cell function. One of the test techniques provides responsivity as a function of the wavelength of incident energy, from 300 to 1,800 nanometers. This technique provides the absolute spectral response measurement, and ASR simply tells how a solar cell (or any other photosensitive device) responds to different wavelengths of light, in units of amps per watt of energy incident on the cell, or A/W. ASR is a standard indicator of solar cell performance, and the new system reduces ASR uncertainty from plus or minus 2 percent to plus or minus 0.5 percent in the visible spectrum.

The other technique scans a focused laser beam (at one of four discrete wavelengths) over the surface of the cell to determine responsivity as a function of position. This laser beam induced current measurement is a spatial mapping of a solar cell's responsivity to a laser wavelength in absolute units (A/W) or relative to peak response. The Sandia test system recently supported an industrial customer who was developing a new photoemissive material. As Paul Schanwald, a photovoltaic specialist recalls, "The customer provided a proprietary process to make this complex surface material. Using the laser beam induced current method, we found unexpected nonuniformities, a discovery that led the customer to make effective process improvements."

The system as a whole contains features that provide unprecedented accuracy in ASR measurements of solar cells and photodiodes, and unique information on responsivity versus position. These features include a common beam path for both laser and monochromator-based light sources, split beam for continuous light-level reference, reference detectors calibrated by the National Institute of Standards and Technology, white-light bias capability, accurate spatial resolution, and temperature control for the test device.

Periodically, the American Society for Testing and Materials asks nine national labs to test a set of solar cells and compares the results. When Schanwald and his colleagues tested 14 solar cells as part of this comparison earlier in 1993, the results confirmed the quality of Sandia's new system, showing a clear superiority

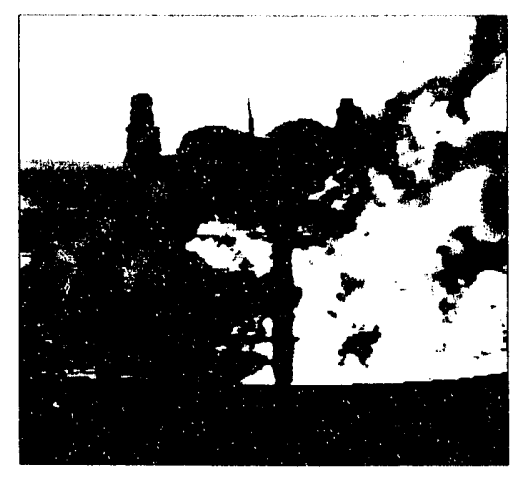

The test fire in full flame. The tube at the left side carries instrumentation and gas lines to the simulated case.

The results confirmed the quality of Sandia's new system, showing a clear superiority in accuracy over other methods. 
The spectral response test set-up at Sandia. The movable stage can scan a laser or light beam over the surface of a solar cell or photosensitive material to determine the efficiency of light utilization. in accuracy over other methods. "This system will lead to more accurate testing of solar cells and photosensitive devices," Schanwald predicts. "We will use this new accuracy to support industry requirements as well as new test and analysis methods we are developing." 团

For more information, call

Paul Schanwald, Org. 6219, (505) 844-3786.

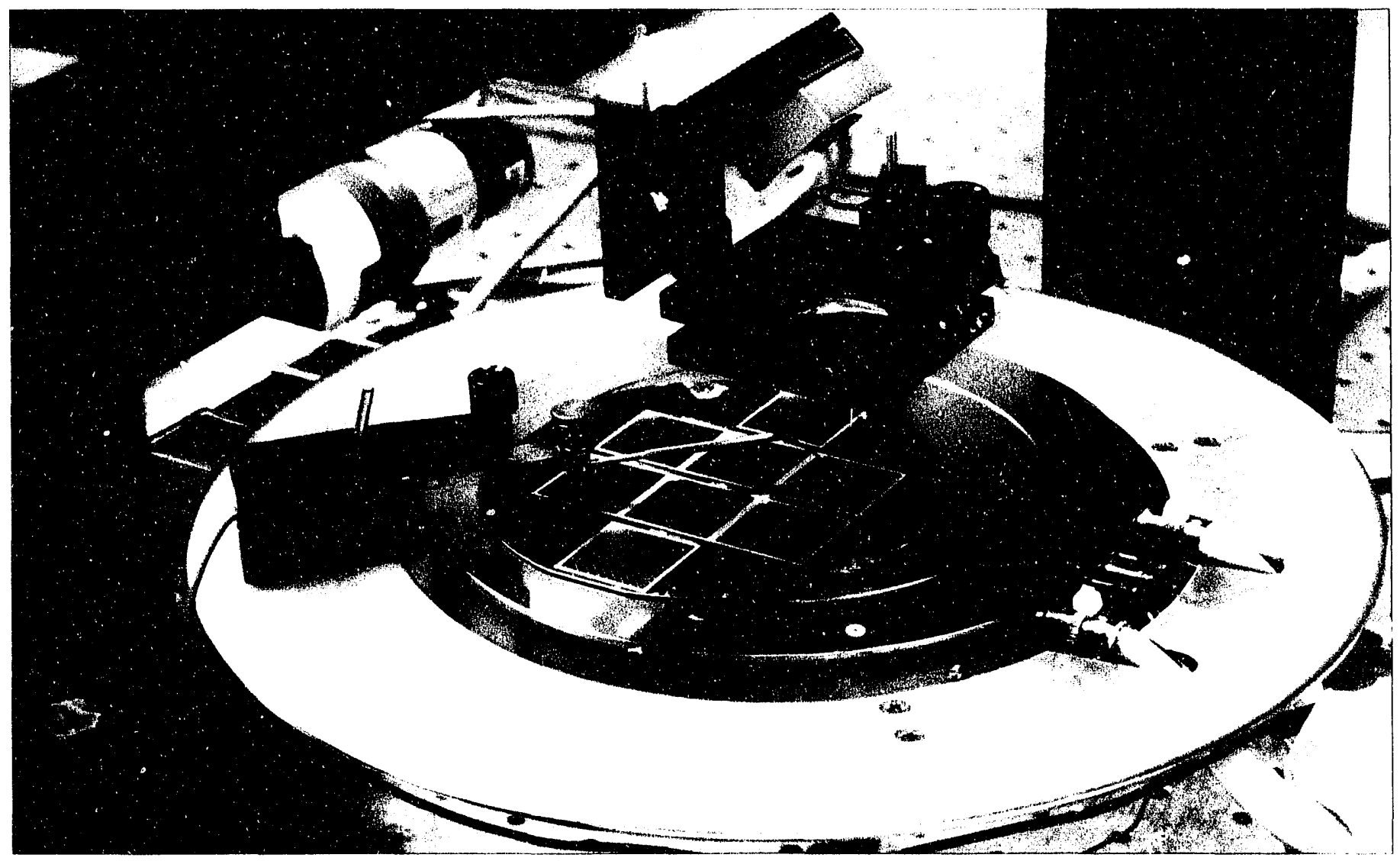

Testing Technology

is published by Planning \& Staff Support, Sandia National Laboratories, to facilitate technology exchange with industries, universities, and government agencies.

Director: Virgil Dugan

Publications manager: lames A. Leonard Publications support manager: Lori Parrott Lead editor: Bob Goetsch

Scientific editors: H. L. Floyd, Linda Doran Art director: Janet lenkins
This report was prepared as an accourt of vork sponsored by the United States Government. Neither the United States Covernment nor any agency contraciors, subcontractors, or their ermployens, mair any warranty, express or implied, or assumes any legal liability or responsibility lor the acculacy, completeness, or uselulness of any intormation, apparatus, product, or process disclosed, of represents that its use would not intringe privately owned rights. Reference herein to specific commercial product, process, or service by does not necessarily constitute or imply its endorsement recommendation, or favoring by the United States
Government, any agency thereol or any of their contractors or subrontractors. The views and opinions expressed herein do not necessarily rellect those of the of their contractors. Report number SAND9 3.1518, DOt Distribution Code UC900. Printed in the United States of America Available trom

National Technical Information Service S.S. Department of Cornmerce S2.8 Port Royal Road

NTis price couges: 22161

Printed copy: A02; Microfiche copy: A01 requests for additional copies to the address

Thu wo (SOS) 844.1392. by the US. Departing of tinergy under supported by the U.S. Departm

\section{SANDIA TECHNOLOGY BULLETIN}

Corporate Publications Dept. 4526

Sandia National Laboratories

P.O. Box 5800

Albuquerque, NM 87185-5800

address correction requested

\section{BULK RATE}

U.S. POSTAGE

PAID

Albuyuerque, New Mexico

Permit No. 232 

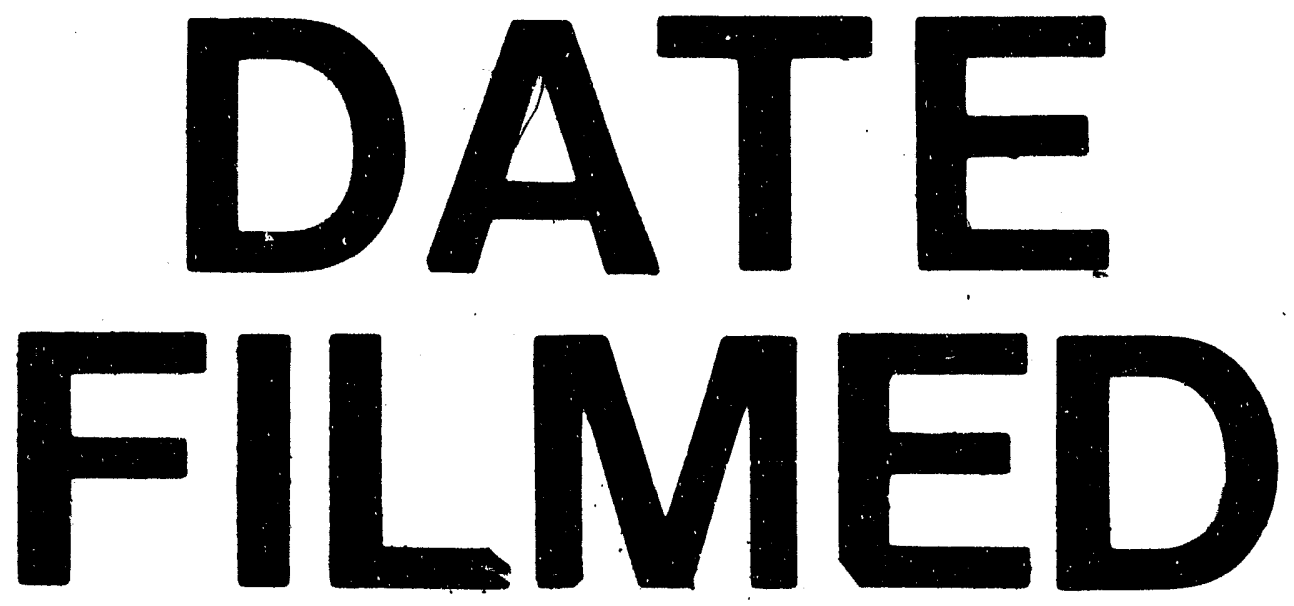

$10 / 15 / 93$ 
